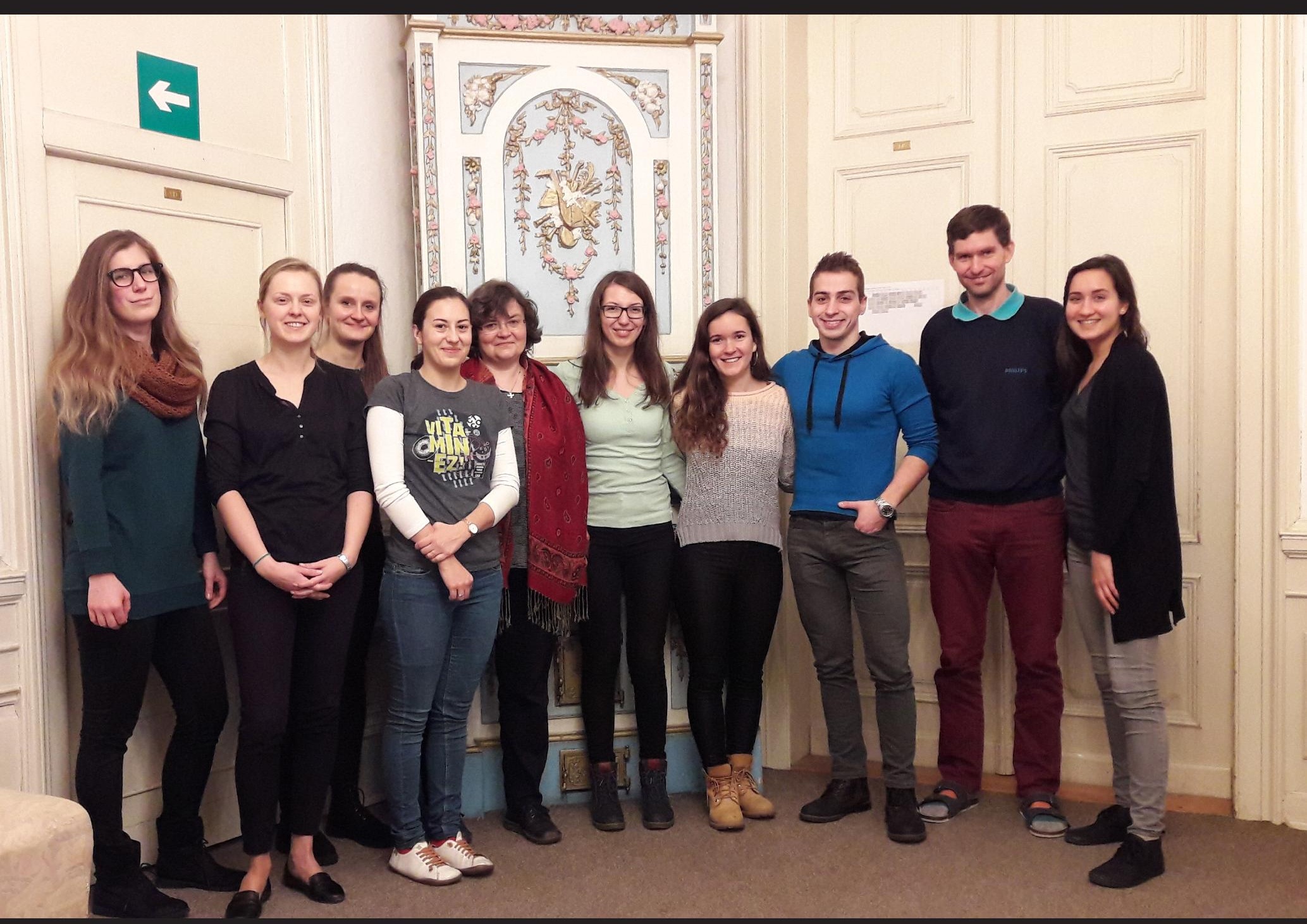

ALUNOS E PROFESSORES DO DEPARTAMENTO DE ESTUDOS LUSO-BRASILEIROS, NO PALÁCIO OETTINGEN,QUE ABRIGA TANTO 0 DEPARTAMENTO COMO TAMBÉM O CENTRO DE LÍNGUA PORTUGUESA DO INSTITUTO CAMÕES: TEREZA HORÁKOVÁ, ŠTĚPÁNKA HULÁKOVÁ, PAVLÍNA JURAČKOVÁ, MICHAELA ZOE PATOČKOVÁ, ŠÁRKA GRAUOVÁ (PROFa DE LITERATURA), MICHAELA FORETOVÁ, LUCIE PUSKÁSOVÁ, MARTIN FOLVARČNÝ, JAN HRICSINA (PROFO DE LINGUÍSTICA) E BARBORA SÝKOROVÁ 


\title{
ESTUDOS LUSO-BRASILEIROS NA UNIVERSIDADE CAROLINA DE PRAGA
}

\author{
Šárka Grauová
}

\section{ALGUMAS CONSIDERAÇÕES HISTÓRICAS}

Durante a maior parte de sua história, a atual República Tcheca fazia parte de estados maiores, principalmente de língua alemã. Até a metade do século XIX a segunda língua dos eruditos era o alemão, que dava acesso à ciência e à cultura universal. Foi só em 1882 que a Universidade Carlo-Fernandina de Praga se dividiu em universidade tcheca e universidade alemã. Mais ou menos na mesma época, um movimento literário ao redor da revista Lumír cumpria o programa de "abertura das janelas sobre a Europa" e lançava uma concepção moderna da tradução.

Findo o Império Austro-Húngaro em 1918, além da necessidade inerente a um país pequeno de se comunicar com o mundo, ter especialistas em línguas e culturas de outras nações fazia parte do orgulho do país independente. Desde o século xx, leitor tcheco culto não aceita mais traduções intermediárias nem mesmo em caso de línguas-fontes pouco comuns como o islandês ou georgiano. Atualmente, na Faculdade de Letras da Universidade Carolina, ensinam-se cerca de noventa línguas.

Como mostrou uma pesquisa recente de Filip Vavř́nek, a origem dos Estudos Portugueses (designação Estudos Luso-Brasileiros só entrou em vigor em 2006) na Faculdade de Letras da Universidade Carolina data de 1928, quando o dr. Jaroslav Cechl (1880-1954), formado em Filologia francesa e alemã, começou a dar cursos 
livres de língua portuguesa. Cechl, que teve a oportunidade de fazer várias viagens de estudos a Portugal, algumas das quais financiadas pelo Ministério da Educação tchecoslovaco, nunca fez parte do corpo docente da Faculdade. Apesar disso, já no fim de sua militância lusitanista, conseguiu encontrar um aluno que deu continuidade ao seu zelo de professor e levou seu esforço a um patamar mais alto. Zdeněk Hampl (1929-1986) conheceu o seu mestre durante os estudos secundários. Formou-se em Filologia inglesa e hispânica e, graças a um empenho fora do comum, virou tradutor, pesquisador em linguística, lexicógrafo e divulgador de literaturas de língua portuguesa, chegando ao nível de professor livre-docente em 1965. Entretanto, desde 1957, seus esforços foram coroados pela fundação do curso Filologia Portuguesa como licenciatura (o qual, a essa altura, supunha cinco anos de estudos concluídos com uma "tese de fim de curso") no âmbito do Departamento de Filologia Românica. Embora sua carreira profissional tenha sido interrompida aos 52 anos, por motivos de saúde, Hampl elaborou vários manuais e dicionários de português do Brasil, traduziu obras de historiografia literária - História da literatura portuguesa [1955] de António José Saraiva e Óscar Lopes e História da literatura brasileira [1955], de Antônio Soares Amora - foi também tradutor de uma vintena de livros de literatura portuguesa e brasileira, geralmente de índole realista que, embora fosse uma imposição do regime possivelmente coincidia com seu gosto pessoal. Dentro desta perspectiva, traduziu Jorge Amado e, talvez por indicação do mesmo, Castro Alves. Não sem deixar de fazer algumas escolhas curiosas, entre as quais, por exemplo, a tradução do Livro de uma sogra [1895], de Aluísio Azevedo.

\section{REVOLUÇÃO DE VELUDO: ANTES E DEPOIS}

A Revolução de Veludo de novembro de 1989, que deu por findo o regime totalitário, constituiu um verdadeiro divisor de águas nas ciências humanas, que haviam sido, desde 1948, alvo da maior pressão do regime, o qual mantinha controle ideológico-político por exemplo sobre a admissão dos alunos na Universidade, sobre a escolha dos professores e sua carreira acadêmica, sobre os temas pesquisados e a produção intelectual em geral.

Antes de 1989, a abertura dos cursos dependia inteiramente do Ministério da Educação. No âmbito da filologia moderna, havia cursos filológicos principais que abriam todos os anos, como o russo, o inglês, o francês ou o alemão. Não sendo possível fazer um curso único, em fevereiro de cada ano o Ministério anunciava as combinações 
de cursos duplos pelas quais os alunos podiam optar. Por exemplo, o português abriu em 1969, 1974, 1977, 1979, 1981, 1983 e $1987^{1}$ e, em todos esses vinte anos, as combinações permitidas limitaram-se ao espanhol, francês, inglês, italiano e aos estudos africanos. ${ }^{2}$ Assim, o português se tornou destino de muitos alunos os quais, por vontade própria, nunca optariam por essa grande incógnita que era o mundo de língua portuguesa como sucedeu, entre outros, à autora destas linhas.

Durante quatro anos, os alunos do curso seguiam um plano fixo, sem disciplinas facultativas, do qual faziam parte também matérias como História Internacional do Movimento Operário, Filosofia Marxista-Leninista, Economia Política, Comunismo Científico, Defesa da Pátria Socialista para as alunas e Preparação Militar para os alunos.

Desde o afastamento de Hampl por doença, em 1983, a Seção Portuguesa do Departamento de Filologia Românica tinha apenas uma professora interna que dava aulas de língua prática e disciplinas linguísticas. As aulas da literatura foram ministradas por Eduard Hodoušek (1921-2004), redator incumbido de literaturas de língua espanhola e portuguesa em Odeon, uma editora estatal que se ocupava de um mapeamento sistemático da Literatura Universal, especialmente das obras dos grandes autores do passado.

\section{SITUAÇÃO ATUAL}

Hoje em dia, o Departamento de Estudos Luso-Brasileiros (DELB) do Instituto de Estudos Românicos conta com dois professores de língua e de linguística e dois professores de literaturas de língua portuguesa.

Desde 2004, a Faculdade abriga o Centro de Língua Portuguesa do Instituto Camões, sendo o seu diretor também leitor de português. Em 2006, o Departamento acolheu sua primeira leitora brasileira, pertencente à Rede Brasil Cultural do Itamaraty. Infelizmente, em 2017, o leitorado perdeu o apoio da Embaixada do Brasil e foi suspenso. No entanto, assim como os professores, nossos alunos ainda podem aproveitar de convênios existentes com o Brasil. No âmbito da Universidade, desde 2010, existe um

\footnotetext{
1 VAVŘínek, Filip: Portugalistika na FF UK: vznik a dějiny oboru. Praha: FF UK, 2016, p. 48. [on-line]. Disponível em: https://is.cuni.cz/webapps/zzp/detail/137567/. Acesso em: 15 nov. 2017.

2 Idem, p. 2 o.
} 
convênio com a Faculdade de Filosofia, Letras e Ciências Humanas da Universidade de São Paulo, FFLCH-USP, e outro, posterior, com a Universidade Federal do Rio Grande do Sul, ufrgs. No nível da Faculdade, existe um convênio com o Instituto de Estudos Brasileiros da Universidade de São Paulo, IEB-USP, e, atualmente, estamos criando outro convênio com o Instituto de Letras da Universidade Federal Fluminense, UfF.

Como em todas as universidades europeias, os Estudos Luso-Brasileiros na Universidade Carolina contemplam a graduação e a pós-graduação. O doutorado se realiza dentro de campos mais largos de Linguística e Língua Românicas. Na Faculdade existe ainda o curso de Estudos Ibero-americanos, esse com pós-graduação e doutorado, ambos centrados nos estudos histórico-políticos.

A graduação é de três anos e segue o tradicional esquema filológico que junta linguística, literatura e os respectivos estudos teóricos. Como os alunos entram sem maiores conhecimentos de português, o curso tem uma grande carga horária de língua prática. Além disso, oferece um ano de Panorama de Literatura Portuguesa, um ano de Panorama de Literatura Brasileira e, no terceiro ano, um semestre de Literatura Portuguesa do Século xx e outro de Literatura Brasileira da mesma época. Outras disciplinas ligadas expressamente ao Brasil são História do Brasil (semestral) e Cultura Brasileira (semestral). No exame final, os alunos discorrem sobre uma lista de cinquenta obras literárias portuguesas e brasileiras, majoritariamente em tradução tcheca. Outra parte do exame consiste em uma dissertação de licenciatura com um mínimo de quarenta páginas ( 72 mil caracteres). Formamos ao redor de oito alunos por ano.

O plano de estudos da pós-graduação, de dois anos, é mais complexo. Os alunos têm uma parte das matérias compartilhadas, mas em outra parte podem escolher entre o Ramo Linguístico e o Ramo Histórico-Cultural. Na literatura, as matérias obrigatórias para todos são: Representações de Identidade Portuguesa/ Brasileira em Literatura (dois cursos semestrais) e Literatura Portuguesa/Brasileira Contemporânea (num esquema idêntico). Além disso, o Ramo Histórico-Cultural oferece um leque de matérias semiopcionais, algumas das quais relacionadas à América Latina. Uma ênfase especial é dada ao curso de Tradução Literária, que os alunos interessados podem repetir cada ano.

Uma tradição herdada do passado já meio longínquo é a possibilidade de "cursos duplos". Nestes, os alunos podem combinar livremente dois cursos ministrados na Faculdade, tendo assim as suas obrigações nos dois um pouco reduzidas (por exemplo, a lista de leituras obrigatórias é diminuída, alguns exames são menos abrangentes etc.). Durante o primeiro ano, o aluno opta por um dos cursos (o "curso 
de diploma"), no âmbito do qual escreve sua dissertação de mestrado. A dissertação é normalmente escrita em tcheco e tem o mínimo de sessenta páginas (108 mil caracteres).

Nos últimos anos, os Estudos Luso-Brasileiros de Praga começaram a atrair alunos das Universidade Masaryk, de Brno, e Universidade Palacký, de Olomouc, onde também há cursos de Estudos Portugueses mas, mesmo assim só conseguimos formar ao redor de três ou quatro alunos por ano.

\section{PESQUISA}

Os temas de pesquisa desenvolvidos pelos professores do DELP são bastante variados, dependendo do enfoque de cada um.É preciso levar em conta que, além de professores universitários, os membros do DELP realizam uma ponte entre a cultura tcheca e as culturas de língua portuguesa e, por isso, muitas vezes, têm que combinar a pesquisa acadêmica com a divulgação, com a tradução literária e com outras tarefas que visam um enriquecimento da cultura tcheca com aportes lusófonos.

Os professores do DELB também participam dos programas de pesquisa mais amplos. Na linguística trata-se especialmente dos estudos de corpus; a pesquisa dos professores de literatura do Instituto de Estudos Românicos se debruça sobre a Literatura da Virada do Século, tema de dois livros publicados em 2016 e 2017, dos quais um, com o título Dusk and Dawn, está escrito em inglês, francês e espanhol.

Um projeto novo está se formando ao redor de um Grupo de Trabalho Tradição e Modernidade nas Fronteiras das Culturas que coordeno.

\section{TRADUÇÕES}

Nas atividades do DELB, o fomento da tradução tem grande importância. Com o intuito de encorajar os jovens tradutores de até 35 anos e fornecer-lhes um feedback, o DELB iniciou em 2009 o "Prêmio Hieronymitae Praguenses", um concurso de tradução para jovens tradutores de português do país inteiro. Organizado com o apoio financeiro do Instituto Camões e, intermitentemente, da Embaixada do Brasil, o concurso é anual, e o júri integrado por professores das três universidades tchecas que oferecem cursos de português. 
Um projeto especial que nasceu no DELB é a Biblioteca Luso-Brasileira, coleção editada junto às editoras Torst e Triáda, em que são publicadas traduções de obras portuguesas e brasileiras, sempre acompanhadas de um estudo de fôlego escrito por um lusitanista. A literatura brasileira está representada por duas excelentes traduções que nossa colega e grande tradutora Vlasta Dufková, hoje aposentada, fez de Burití e Dão-la-la-lão, de Guimarães Rosa, mas também por Gonzaga, de Castro Alves, uma tradução de Zdeněk Hampl descoberta nos fundos da biblioteca do Instituto de Teatro e que teve o privilégio de ser comentada por Walnice Nogueira Galvão, e por Budapeste, de Chico Buarque. Em 2018 aparecerão mais dois livros brasileiros, Triste fim de Policarpo Quaresma, de Lima Barreto, que ganhou uma nova tradução, e K.: relato de uma busca, de B. Kucinski.

Šárka Grauová é Professora de Literaturas de Língua Portuguesa na Faculdade de Letras da Universidade Carolina em Praga. É Chefe do Departamento de Estudos Luso-Brasileiros e Presidente da Sociedade Tcheca de Língua Portuguesa. Traduziu Memórias Póstumas de Brás Cubas, de Machado de Assis, Macunaíma, de Mário de Andrade, Boca do Inferno, de Ana Miranda, Budapeste, de Chico Buarque, em 2009, e Triste Fim de Policarpo Quaresma de Lima Barreto, em 2018. Traduziu juntamente com outras três colegas a História da Literatura Brasileira, de Luciana Stegagno-Picchio. Para saber mais sobre a trajetória intelectual de Šárka Grauová recomendamos a leitura de "Estudos Brasileiros Extramuros", entrevista concedida a Walnice Nogueira Galvão, Teoria e Debate, n 110, 1 mar. 2013. 